\title{
Formation of Precambrian sediment ripples
}

\author{
Arising from: P. A. Allen \& P. F. Hoffman Nature 433, 123-127 (2005)
}

Quantitative estimation of environmental properties using sedimentary structures preserved in rocks is complicated by the fact that some relationships between the fluid flow, sediment transport and bed topography are not unique. Allen and Hoffman ${ }^{1}$ propose that large, wave-generated sand ripples (orbital ripples) in Precambrian rocks were generated by sustained, extreme winds driven by rapid climate change after termination of the Marinoan glaciation. We show here that these features could equally well have formed under normal storm conditions in tens of metres of water. We therefore contend that the ripples do not provide direct evidence for a climatic transit after the break-up of a snowball-Earth's global ice cover.

Allen and Hoffman conclude that the observed ripples developed in deep water (depth $h, 200-400 \mathrm{~m}$ ), by waves of unusually large period $(T, 21-30 \mathrm{~s})$ and amplitude $(H$, $7.5-12 \mathrm{~m}$ ). They suggest that a discrete cyclone or hurricane is likely to be too short-lived an event to produce the observed sedimentary structures and that present-day orbital ripples seldom have wavelengths $(\lambda)$ exceeding $1 \mathrm{~m}$, both of which we contest.

A bathymetric survey ${ }^{2}$ of the continental shelf off North Carolina in the United States found ripples with wavelengths of up to $4 \mathrm{~m}$ and a median grain diameter $(D)$ of $0.1-5 \mathrm{~mm}$ covering the shelf at $h$ values of $20-40 \mathrm{~m}$. Field observations link formation of these ripples to specific hurricanes and tropical storms. Measured values of $T$ and $H$ for the water waves developed during these events commonly exceeded $60 \mathrm{~s}$ and $3 \mathrm{~m}$, respectively. Detection of this bed topography seems to be limited by instrument resolution, rather than by a paucity of these features on the sea floor ${ }^{2}$.

Critical shear stress $\left(\psi_{c}\right)$ for the initial motion of a particle of size $D$ provides a minimum bed-stress condition for ripple formation ${ }^{1-3}$. An upper limit for bed stress associated with steep orbital ripples is $3 \psi_{\mathrm{c}}$ (ref. 2 ). This narrow range in bed shear stress plus the mean value for $\lambda$ constrain the associated near-bed flow field ${ }^{2,3}$ (Fig. 1). With these parameters, $T$ is the only surface-wave property that can be estimated from sedimentary deposits ${ }^{1,3}$. Airy wave theory relates wavelength $(L), H$ and $h$ to near-bed flow conditions $\mathrm{s}^{1,3}$; however, an infinite combination of these variables can produce the same near-bed conditions (Fig. 1). Allen and Hoffman only consider transport conditions at $\psi=\psi_{0}$ which yields a maximum estimate for $T$. For $\psi=3 \psi_{c}$, Tis reduced by a factor of $\sqrt{ }(1 / 3)$ (Fig. 1). Flanks of some preserved ripples exceed the angle of repose, indicating deformation and
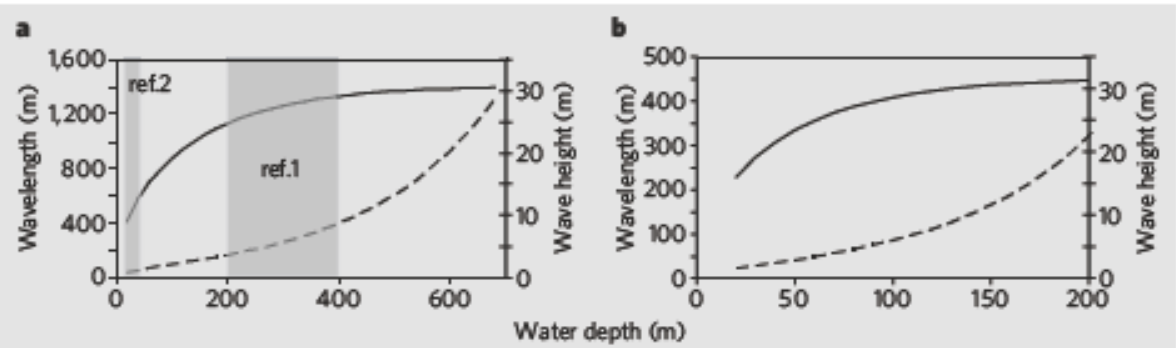

Figure 1 Height (dashed lines) and length (full lines) of possible ripple-forming surface waves calculated for a range of water depths. a,b, Calculations using Airy theor $y^{2,3}$ with a, $T=30 \mathrm{~s}, \psi=\psi_{c}$ and $\mathrm{b}, T=17 \mathrm{~s}$, $\psi=3 \psi_{c}$, where $T$ is the wave period and $\psi\left(\psi_{c}\right)$ is the (critical) shear stress. Ranges of wave conditions associated with reported water depths from refs 1 and 2 are indicated by grey boxes. For the figure, we used wavelength $\lambda=3.5 \mathrm{~m}$ and $\psi_{c}$ estimated from grain size $D=0.12 \mathrm{~mm}$ (for methods, see ref. 2). Using entire ranges of $D(0.12-0.5 \mathrm{~mm})$ and $\lambda(1.5-5.4 \mathrm{~m})$ reported by Allen and Hoffman, and $\psi_{\mathrm{c}} \leqslant \psi \leqslant 3 \psi_{\mathrm{c}}$ (ref. 2), yields $T$ values of 8-41 s. We calculated the aggradation rate as $r=m / T$, where $m=0.40 \mathrm{~cm}$ is the mean cross-bed thickness in Fig. $2 c$ of ref. 1 . When $T$ is between 8 and $41 \mathrm{~s}, r$ is $0.58-2.99 \mathrm{~cm} \mathrm{~min}^{-1}$.

making the measured steepness values inexact.

More important, Allen and Hoffman assume, without justification, that wind of unlimited fetch and duration generated the long-period surface waves producing the bedforms. Their estimates for $H$ are based on this model and these values, in turn, are used to calculate $h$. Their environmental reconstruction represents a possible, but non-unique, inversion of the geological data. Modern storm-generated waves of similar period produce orbital ripples of the same morphology and grain size $e^{2}$ as the Marinoan examples, but under conditions of much smaller $h, H$ and $L$. An independent constraint on any one of these three variables is necessary for closure. The most reasonable procedure would be to estimate water depth based on the physiographical position of ripples found within the ancient basin.

Perhaps the most remarkable aspect of the reported stratigraphy ${ }^{1}$ is the continuous vertical climb of the ripples. A rate of deposition associated with this dimb is tightly constrained by $T$, and is calculated to be about $1 \mathrm{~cm} \mathrm{~min}^{-1}$. This high rate seems to rule out spontaneously precipitating carbonate 4 as the sediment source for the ripples. At this rate, the entire sequence shown in Fig. 3 of ref. 1 could have been deposited in less than $3 \mathrm{~h}$. A small number of short-duration events do not place any constraint on associated climate conditions.

Our results (Fig. 1) show that the preserved orbital ripples ${ }^{1}$ could have formed under rather mundane environmental conditions ${ }^{2}$, and therefore do not provide evidence for extreme climate change. We wish to make clear that our analysis does not address larger issues of the snowball-Earth hypothesis ${ }^{4}$, but rather serves to show that small-scale observations must be carefully placed within abasin-scale context to produce a unique set of environmental conditions associated with the accumulation of the observed sedimentary deposits.

Douglas J. Jerolmack, David Mohrig

Department of Earth, Atmospheric and Planetary Sciences, Massachusetts Institute of Technology, Cambridge, Massachusetts 02139, USA

e-mait: douglasj@mit.edu

1 Allen, P.A. \& Hoffman, P. F. Nature 433, 123-127 (2005).

2. Ardhuin, F.et al. J. Geophys Res. 107, 3143(2002).

3. Komac, P. D.\&. Millec, M. C J.Sedim. Petrol. 43, 1101-1110 (1973)

4. Hoffman, P. F. et al. Science 281, 1342-1346 (1998).

doi:101038/nature04025

\section{PALAEOCLIMATOLOGY}

\section{Allen and Hoffman reply}

Reply to: Jerolmack, D. J. \& Mohrig, D. Nature doi:10.1038/nature04025(2005)

Jerolmack and Mohrig ${ }^{1}$ suggest that the waveripple structure we describe ${ }^{2}$ from cap carbonates deposited in the aftermath of the Marinoan glaciation was created under storms or hurricanes similar to those experienced today on certain oceanic coasts, citing a documentation of large wave ripples on the seabed off the coast of North Carolina. Side-scan sonar images indicate that such ripples have wavelengths of $0.4-3 \mathrm{~m}$, although the ripple 